\title{
Autonomous Light-Weight Heliostat with Rim Drives
}

\author{
Andreas Pfahl ${ }^{1}$, Michael Randt ${ }^{2}$, Carsten Holze ${ }^{3}$, Stefan Unterschütz ${ }^{4}$ \\ ${ }^{1}$ German Aerospace Centre (DLR), Institute of Solar Research, Pfaffenwaldring 38-40, 70569 Stuttgart, Germany, \\ Phone: +49-7116862479, Fax: +49-71168628032, E-mail: Andreas.Pfahl@dlr.de \\ 2 TRINAMIC Motion Control GmbH \& Co KG, Waterloohain 5, 22769 Hamburg, Germany, E-mail: Randt@trinamic.com \\ ${ }^{3}$ toughTrough $\mathrm{GmbH}$, Fahrenheitstrasse 1, 28359 Bremen, Germany, E-Mail: carsten.holze@toughtrough.com \\ ${ }^{4}$ Hamburg University of Technology, Institute of Telematics (E-17), Schwarzenbergstraße 95, 21073 Hamburg, Germany, \\ E-Mail: stefan.unterschuetz@tu-harburg.de
}

Available online at http://www.sciencedirect.com/science/article/pii/S0038092X13001023

(c) 2015 The Authors. Published by Elsevier Ltd. Solar Energy 92 (2013) 230-240

http://dx.doi.org/10.1 016/j.solene r.2013.03.005

\begin{abstract}
Several approaches for cost reduction of heliostats, which fit well to each other, are combined to a new heliostat concept to achieve the current challenging cost objectives: The wind loads are reduced by appropriate manipulators which reduces weight and cost of the heliostat structure and the ground anchor foundation. Laminated mirror facets are of high reflectivity and shape accuracy and of low weight. The low weight is advantageous for the dimensioning of the bearings and regarding energy consumption. Energy consumption is further reduced by a highly efficient drive train. Thus, small capacity of the wireless energy supply of the autonomous heliostat is sufficient which reduces significantly its cost. By the combination of horizontal primary axis with rims and winch wheels a cheap and precise solution for the drives was found. Ray tracing calculations show that the losses due to the compromised angle range are negligible. With the new heliostat concept the current cost goals seem to be achievable.
\end{abstract}

Keywords: wind load reduction; autonomous heliostat with rim drives; sandwich facet; ground anchor foundation

\section{Introduction}

Heliostats are the most important cost element of power tower plants because they typically contribute about $40 \%$ to the total cost of the plants (Kolb et al., 2011). Therefore, in particular the cost of heliostats must be reduced to reach the current challenging cost objectives. To achieve $10 \AA / \mathrm{kWh}$ by solar thermal tower power plants, the heliostat field may cost $120 \$ / \mathrm{m}^{2}$, to reach $6 \$ / \mathrm{kWh}$ it may cost $75 \$ / \mathrm{m}^{2}$ (Gary et al., 2011). With conventional heliostat concepts such a cost reduction seems to be impossible. Beneficially, an impressive amount of unconventional heliostat concepts was found so far as surveyed in (Pfahl, 2014). Based on these concepts and the knowledge about wind loads (Pfahl et al., 2011) and their impact on the annual energy yield (Teufel et al., 2008), a new combination was found which leads to a significant cost reduction. It combines the advantages of the following approaches (Fig. 1): sandwich mirror facets (Holze et al., 2012), wind load reduction (Holze, 2011), prefabricated compact ground anchor foundation, wireless communication and energy supply (Kubisch et al., 2011), horizontal primary axis (Schramek and Maass, 2010), rim drives (Mancini, 2000) with winch wheels and locking during stow (Pfahl, 2013). 


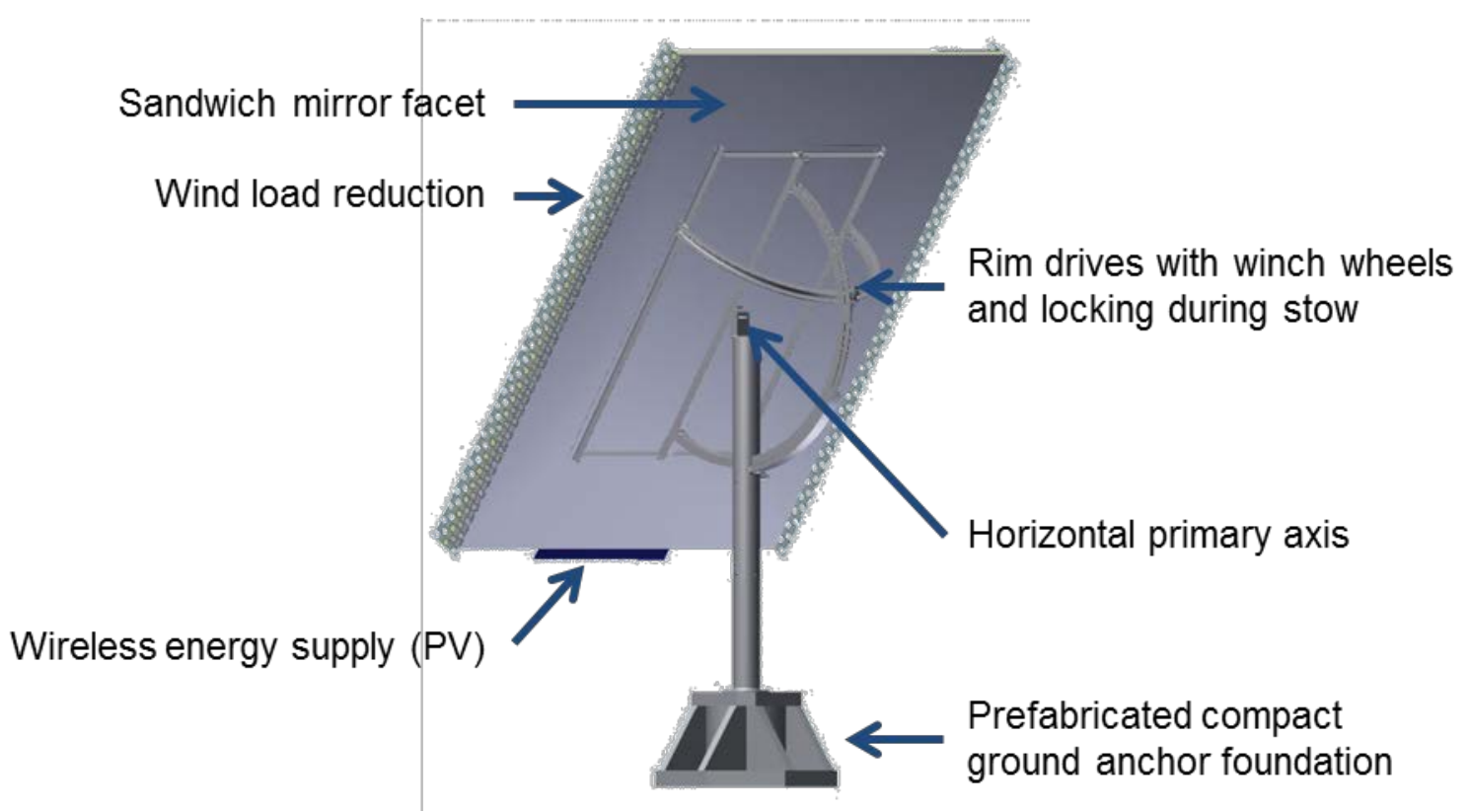

Fig. 1. Autonomous light-weight heliostat with rim drives

Generally, the weight of a product is a measure for its cost for high production rates. The specific weight of heliostats increases with its mirror area by the power of 1.5 by trend (Kolb et al., 2007, A.3). Hence, on the long turn, small heliostats seem to be promising especially if the cost for wiring can be avoided (in particular for small heliostats the cost for wiring is high). For this reason and to start as simple as possible, a heliostat with only one facet is investigated at the beginning. The maximum size of one mirror facet with aspect ratio of 1.2 is $8 \mathrm{~m}^{2}$ because of restrictions in the float glass production process and for transport reasons. In the following, the wind load assumptions, the mechanical structure, the drives and the control of the new heliostat concept is described and rough cost estimation for a heliostat of $8 m^{2}$ is given.

\section{Wind loading and baffle devices for their reduction}

The design criteria for heliostats depend on the environmental conditions of the site. Usually, the systems are installed in flat land scape with corresponding high wind loading. Basic design criteria for the systems are:

- low deformation / slope error due to self-weight effects and additional wind loading of the mirror surface in operation conditions to guarantee specified system efficiency an

- survival of all heliostat components (mirror facets-, supporting structure, drives and pylon) at maximal wind loading in stow position.

The general wind conditions for the design of heliostat systems are given by accordant standards, for example EC 1 (EN 1991-1-4, 2005). Several experimental studies have been performed in the past to determine the relevant wind load coefficients for isolated heliostat as well as for complete heliostat field configurations (e.g. (Peterka et al., 1989), (Peterka et al., 1986) and (Pfahl et al., 2011)). The detailed studies are the current base for the dimensioning of heliostats. At these the turbulence intensity is matched, but not the turbulence spectrum. David Banks (2011) pointed out that without matching the turbulence spectrum the wind loads are presumably overestimated especially for the stow position. This question has to be further investigated and may lead to a reduction of the load assumptions and therefore to lower cost. 
Furthermore, the wind loads can be reduced by a porous "fence" at the frontal edge of the mirror panel. Its impact on the wind loads have been investigated by wind tunnel measurements (not published yet, see Fig. 2).

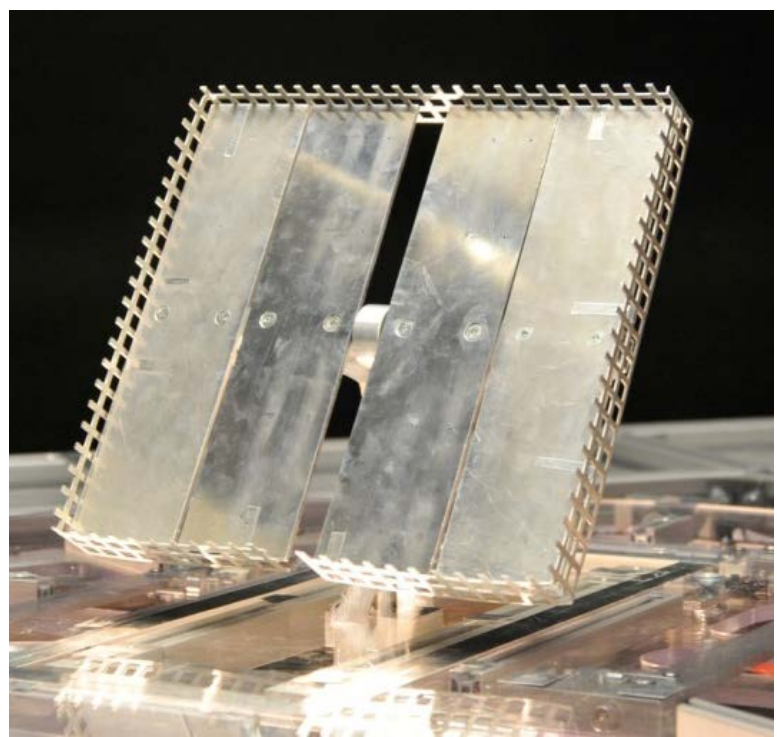

Fig. 2. Heliostat model mounted on six component balance in wind tunnel. The metal grid at the edges has the function of manipulating how the wind passes over the heliostat facet.

The baffle devices are designed to reduce the wind loads when in stow position (horizontal mirror plane). In stow position the heliostat has the smallest cross section area facing the wind. Nevertheless, the highest wind loads may occur for this orientation of the panel because it is the survival position with high possible storm wind speeds. The high overturning moments in stow position are caused by the turbulence level of the natural wind. Turbulent wind has velocity components in all three axis directions. This signifies that the heliostats are attacked by the wind lengthwise and instantaneously also normal to the mirror plane. The incident flow with vertical velocity component separates at the frontal edge causing suction on the other side of the mirror. The resulting pressure difference between top and bottom of the facet leads to high pressure coefficients ( $c_{p}$-values) near the frontal edge (see Fig. 3 and (Gong et al., 2013).

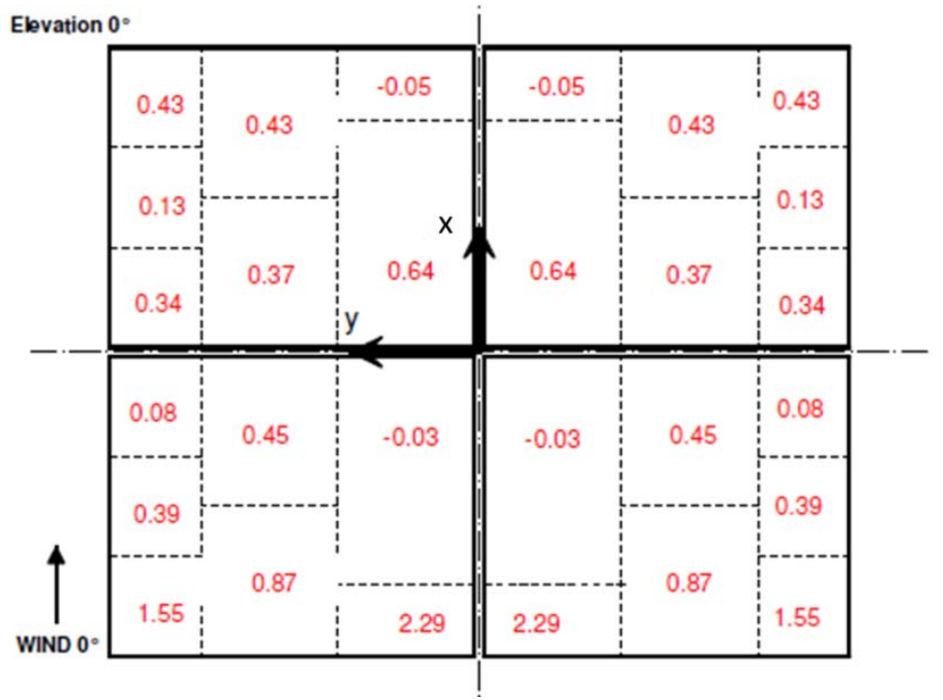

Fig. 3: Pressure coefficient distribution on mirror panel (pressure related to dynamic pressure of mean wind speed in elevation axis height) at point in time with peak overturning moment for heliostat in stow position (Pfahl et al., 2011) 
The peak differential pressure at the frontal edge leads to the peak overturning moment (Fig. 4 left). By a fence like structure at the frontal edge (compare Fig. 2) separation and thus suction is reduced which leads to a reduction of $40 \%$ in the overturning moment (Fig. 4 right).
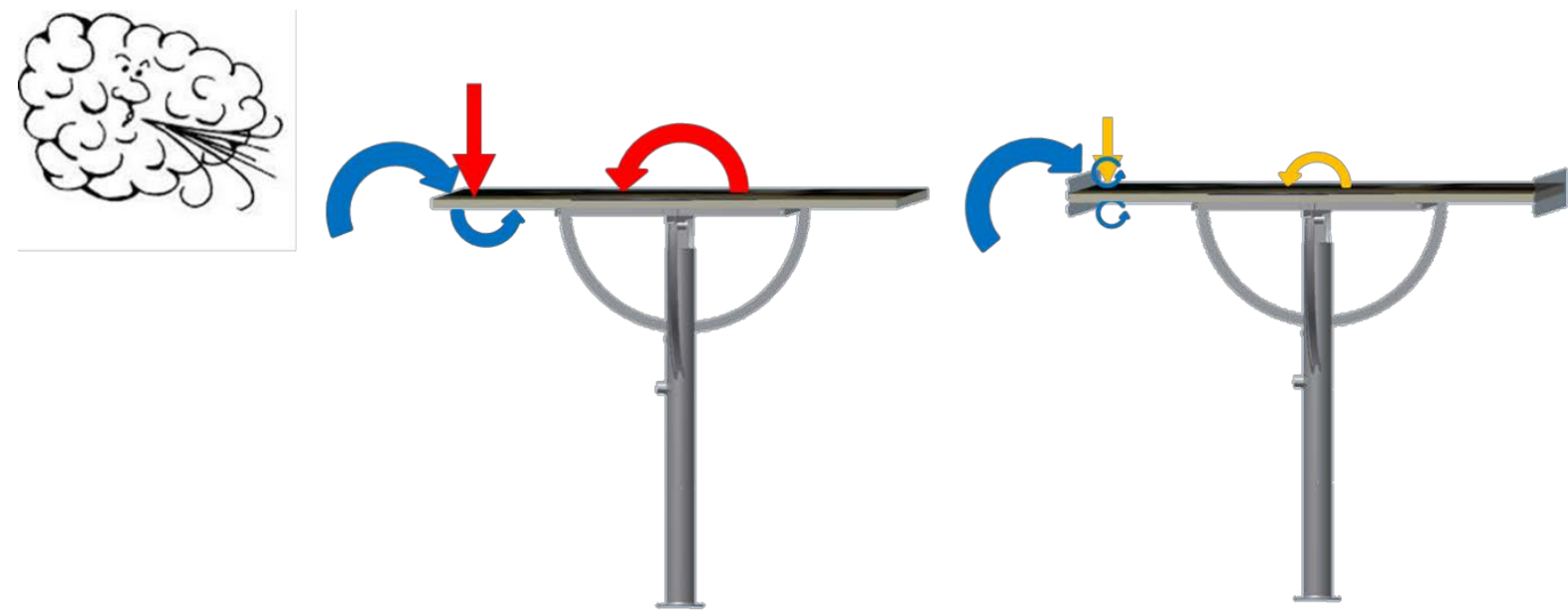

Fig. 4. Left: Turbulence causing high pressure coefficients $c_{p}$ at the frontal edge and a high overturning moment at storm conditions at a heliostat in stow position. Right: Flow manipulators (fence like structures) reducing suction and overturning moment

This load reduction enables a $30 \%$ weight reduction of the mirror facet support, the pylon, the foundation and partly of the mirror facet because the cross-sectional area of tubes is proportional to the load moment to the power of $2 / 3$ (Kolb et al., 2007, A.3). Disadvantage of the baffle devices is that they may cause a small extra effort in cleaning the mirrors. The impact on the dynamic loads has still to be investigated for this case.

\section{Sandwich facet}

Based on the structural loads, a sandwich mirror facet, consisting of a thin glass mirror as front layer, a polyurethane foam core and a steel backward layer, has been optimized. The thin glass may be as thin as $0.95 \mathrm{~mm}$ (featuring a reflectivity of $95.5+/-0.5 \%$ ). The foam core thickness lies around $28 \mathrm{~mm}$ and is a trade-off between sandwich stiffness and cost of material. The steel backward layer is $0.5 \mathrm{~mm}$. All edges are framed and sealed against intruding moisture. The facets can be manufactured as planar mirrors for mechanical bending in an integrated frame or can be manufactured in three dimensions by a precision molding process where the mold is curved in two directions so that the mirror is point focusing. Due to the high self-stiffness of the sandwich itself, no additional stiffeners are needed. The specific structural weight of the mirror facet, including the mechanical interfaces, is below $10 \mathrm{~kg} / \mathrm{m}^{2}$.

Fig. 5 shows three different heliostat facets produced in a precision molding process and mounted on pylons but without drives yet. The photos demonstrate what stage of quality the production process has already reached. The assessment arrived at in this study are based on mass production mirrors not laboratory prototypes. The deviation of the manufactured surface from the ideal shape is called slope error. The slope error of the heliostat facets produced for this study was measured to be $0.6 \mathrm{mrad}$. 


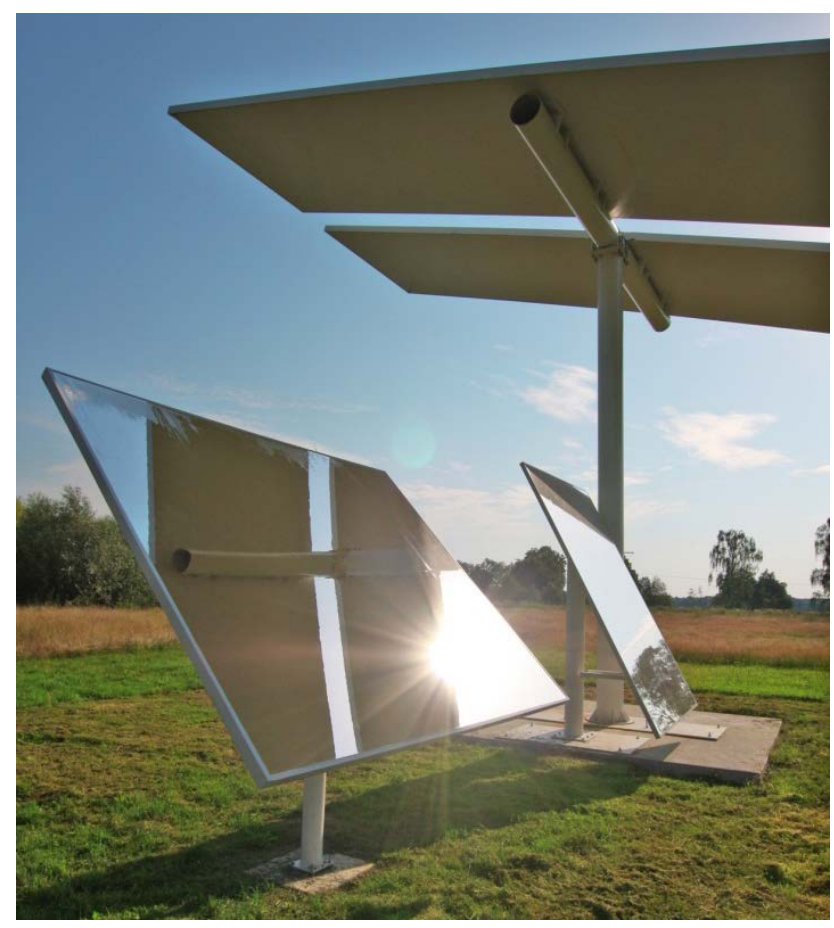

Fig. 5. Laminated mirror facets for heliostats

Assuming costs of $12 \$ / \mathrm{m}^{2}$ for the $0.5 \mathrm{~mm}$ steel back layer, $12 \$ / \mathrm{m}^{2}$ for the thin glass mirrors (compare (Kolb et al., 2007)) and $15 \$ / \mathrm{m}^{2}$ for core and assembly, resulting costs of $40 \$ / \mathrm{m}^{2}$ for the sandwich facet can be realized (for high production rate). The low slope error of $0.6 \mathrm{mrad}$ (measured) corresponds to 2-4\% higher field efficiency compared to facets of typical $1.3 \mathrm{mrad}$ slope error. Together with the $2 \%$ higher reflectivity of thin glass mirrors (compared to $4 \mathrm{~mm}$ glass mirrors) this leads in total to an increase in field efficiency of 4-6\% (Holze et al., 2012). Further advantages are the lower weight, the higher hail resistance (Diver and Grossman, 1999) and generally less mirror breakage. The small realizable curvature radii are important for small power plants with small towers and slant ranges in the range of $30 \mathrm{~m}$ or below.

\section{Concrete-sand foundation}

A foundation system for the heliostat will be developed as a preformed hybrid concrete-sand foundation (Fig. 6) according to DIN 4023, EC 7 (Eurocode 7, 1997). The foundation consists of a prefabricated block on which additionally natural site material (sand, stones) is put to increase weight. Significant cost reduction for the foundation, which typically contributes about $10 \%$ to the total cost (Mancini, 2000), is expected.

To improve the soil's stiffness and strength and to minimize its permeability, geotechnical investigations with soil samples were performed. An improvement of the soil characteristics can be achieved by compaction and/or admixing of substances which includes techniques like soil exchange, deep compaction, consolidation, injections and soil stabilization (e.g. by coating). These methods are standard in coastal protection and are treated as transfer technologies for heliostat foundation design. 

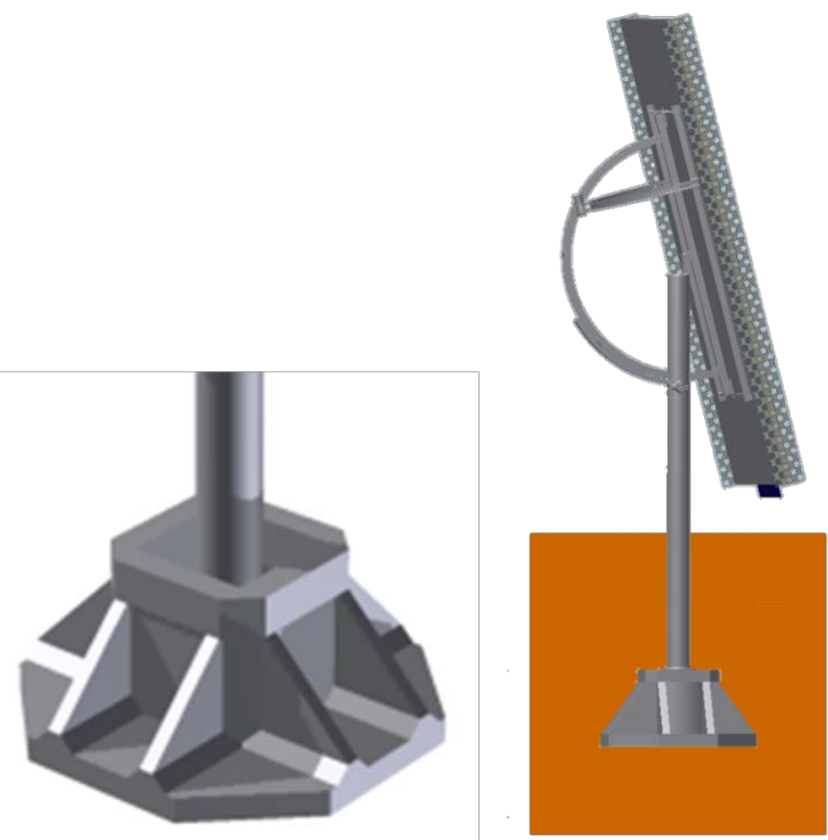

Fig. 6. Prefabricated concrete ground-anchor foundation

\section{Horizontal primary axis with rim drives and winch wheels}

\subsection{Description}

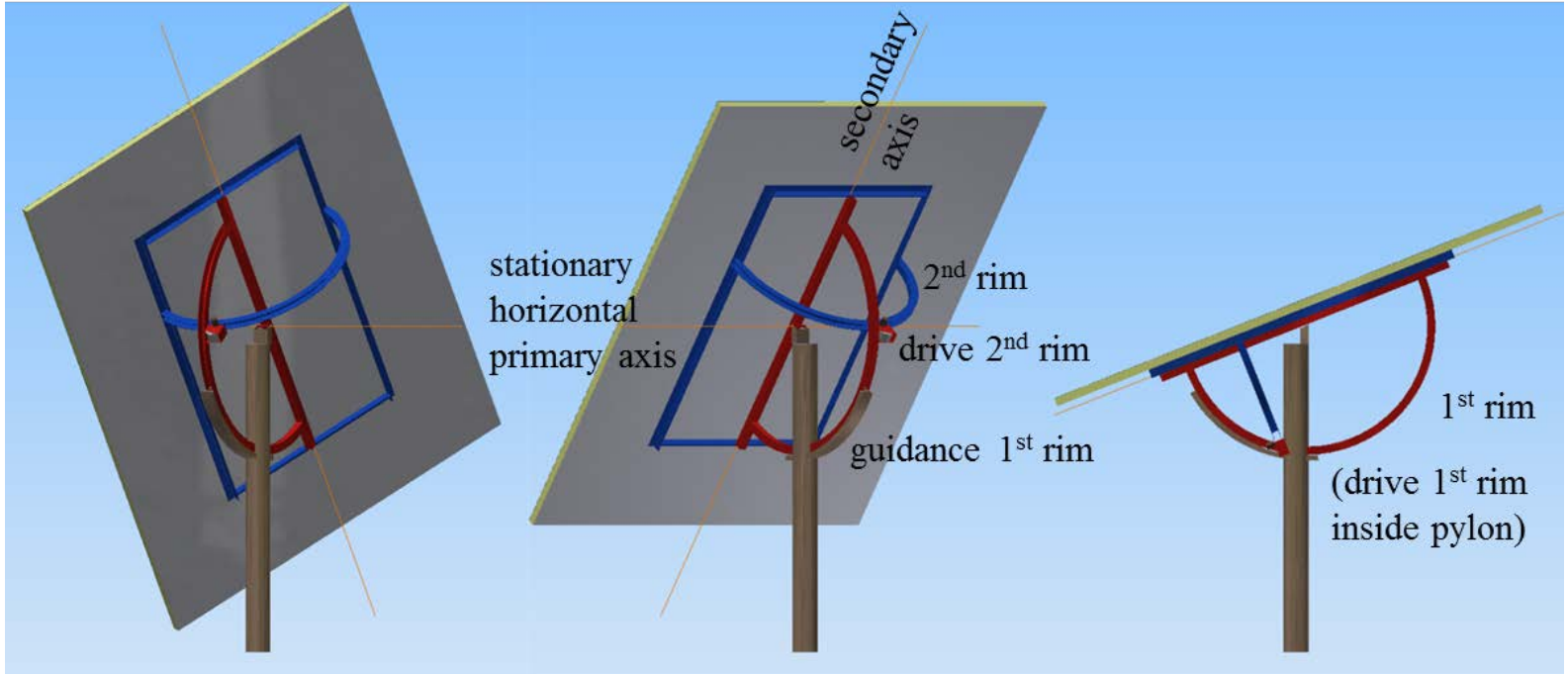

Fig. 7. Heliostat with horizontal primary axis and rim drives; red parts are pivoted only around primary axis, blue parts and sandwich panel are pivoted also about secondary axis

An illustration of a heliostat with horizontal primary axis and rim drives (Pfahl, 2011) is given by Fig. 7 . The $1^{\text {st }}$ rim can be supported by a guidance bar with sliding blocks to increase stiffness (see Fig. 8). 


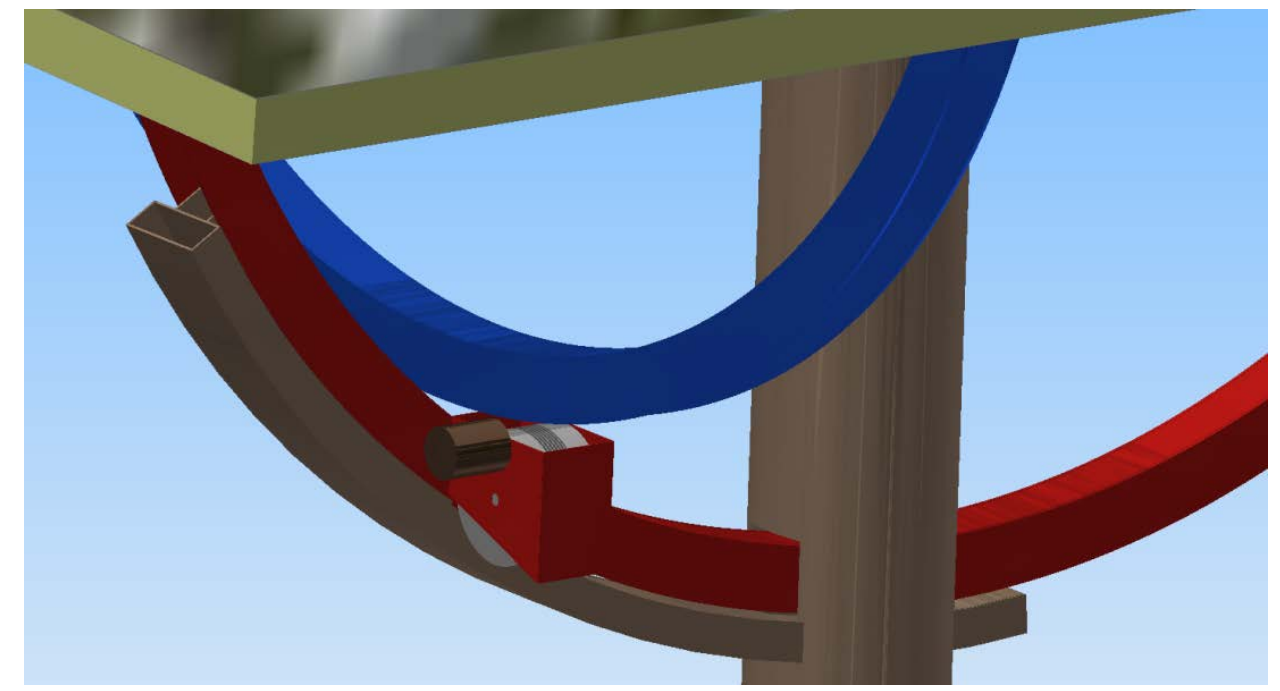

Fig. 8: Guidance bar with sliding blocks to increase stiffness of $1^{\text {st }}$ rim

The $2^{\text {nd }}$ rim is fixed to the mirror panel (see Fig. 7). The drive for the primary axis is mounted at the pylon, the drive for the secondary axis on the first rim. The gears may be realized by chains with bevel wheels or better by winch wheels (see 5.2). Both rims are locked during stow to unload the drives and cables or chains at storm conditions. The advantages cover:

- The loads on the drives are small and the backlash of the drives can be relatively high because of the long lever arm (distance between drives and centre of rotation) realized by the rims, which enables the usage of low cost drives.

- Reduced loads on bearings, mirror panel, upper part of pylon and stow-positionlocking devices during stow.

- Only low cost slide bearings and no ball bearing are needed.

- Rims act partly as counter weights for lower energy consumption.

- Because no low efficient self-locking gears are used the energy consumption of the complete drive train is low which yields lower cost concerning PV cell and energy storage element (e.g. super capacitor) for autonomous operation.

- Higher field density and thus slightly higher field efficiency (1-2\%) because of horizontal primary axis (Prosinečki and Schnatbaum, 2012).

- No mechanical precision components are needed which may increase the local production share.

The drawbacks involve:

- Extra effort for two rims, guidance bar for the first rim, locking devices for stow and sand protection of the gears (but presumably not needed, see 5.2).

- Increased height of the elevation axis, which is defined by half of the diagonal of the mirror panel (see Fig. 7 left) and not by half of the chord length as for conventional elevation-azimuth axes orientation. The increased height leads to somewhat increased wind loads, especially at the pylon base because the wind speed increases with height.

- Somewhat higher mounting efforts on site.

- Low stiffness against wind loading for certain mirror panel orientations during operation (but, according to Teufel et al. (2008), the resulting losses in the annual energy yield of the plant due to deformations of the heliostat at high wind speeds are expected to be negligible). 


\subsection{Winch wheels}

Winch wheels go well together with the rim drive approach. On the one hand, due to the rims, one winch wheel per axis is sufficient because the two cables of each axis are running on the same circular path. Therefore, their change in length and thus their speed are the same (in opposite direction) during rotation, see Fig. 9 left: The two cables of each drive are guided by the U-shaped rim and are running on one single wheel. While one is winded the other is unwinded. Middle: Both cables are unwinded by the same length for horizontal mirror panel. Right: When one cable is further unwinded (right orange cable) the other one is winded (left green cable) by the same length (blue dots) and thus with the same speed. Therefore they can be driven by the same wheel.

On the other hand, the accuracy of the rims may be low when combined with winch wheels. Further advantages of winch wheels are their energetically high efficiency and that they have quasi no backlash which leads to high tracking accuracy.
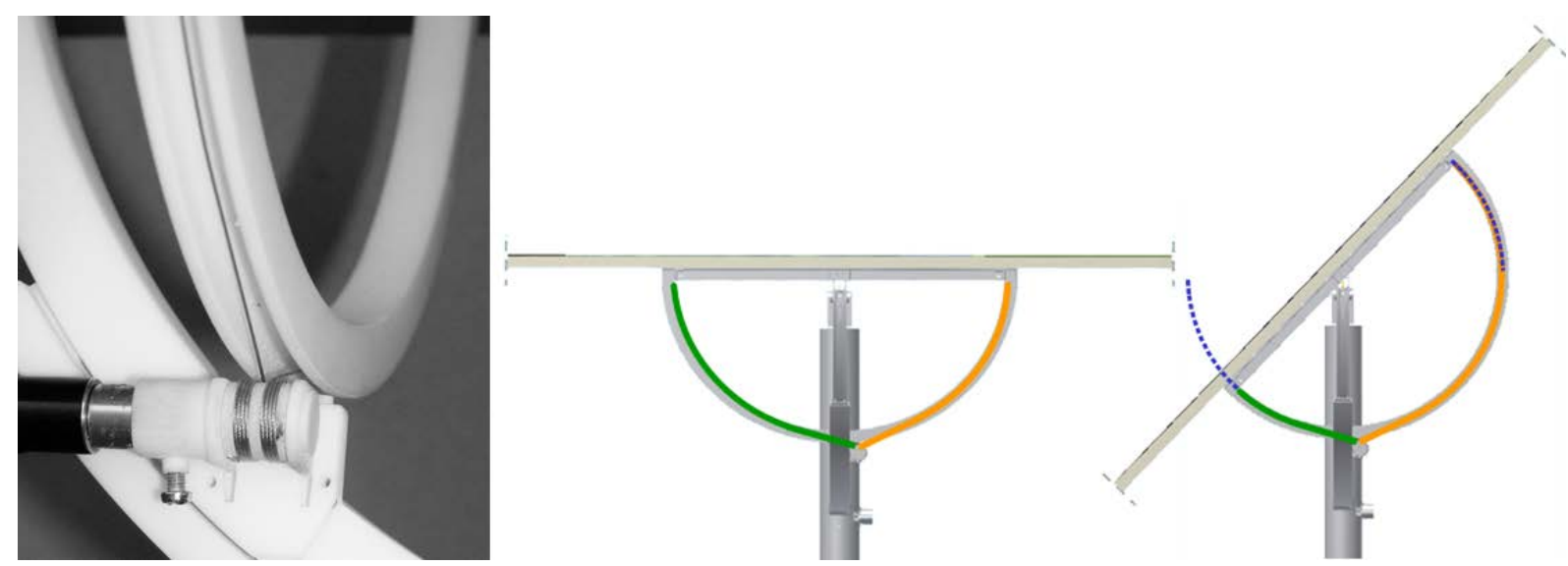

Fig. 9. Left: Winch wheels with rims of model in the scale 1:5. Middle: Same length of both cables for horizontal mirror panel. Right: For both cables the change in length (blue dots) and speed is equal. Therefore they can be driven by one single wheel.

Usually, the steel cables of winches have to be lubricated to reduce wear. Lubricated cables have the drawback that dust and sand could stick on the cables. To avoid this, an extra protection against sand and dust would be required. But, at heliostat application, the loads on the cables are low because they are dimensioned for the maximum gust which occurs rarely. Furthermore, the rotational speed of the winches is extremely low. Hence, it is assumed that wear of the cables is low even if no lubrication is foreseen. Cables which are not lubricated presumably don't have to be protected against sand and dust because sand and dust would not stick on them. The (not lubricated) chains of the drives of Scheffler reflectors (Scheffler, 2006) for example, which have similar operational conditions, are neither protected which never caused any problem although these reflectors are already in operation for many years (personal communication with Wolfgang Scheffler). Nevertheless, to ensure these assumptions, the winch wheel drive system will be tested regarding wear at outdoor conditions. 


\subsection{Angle range limits}
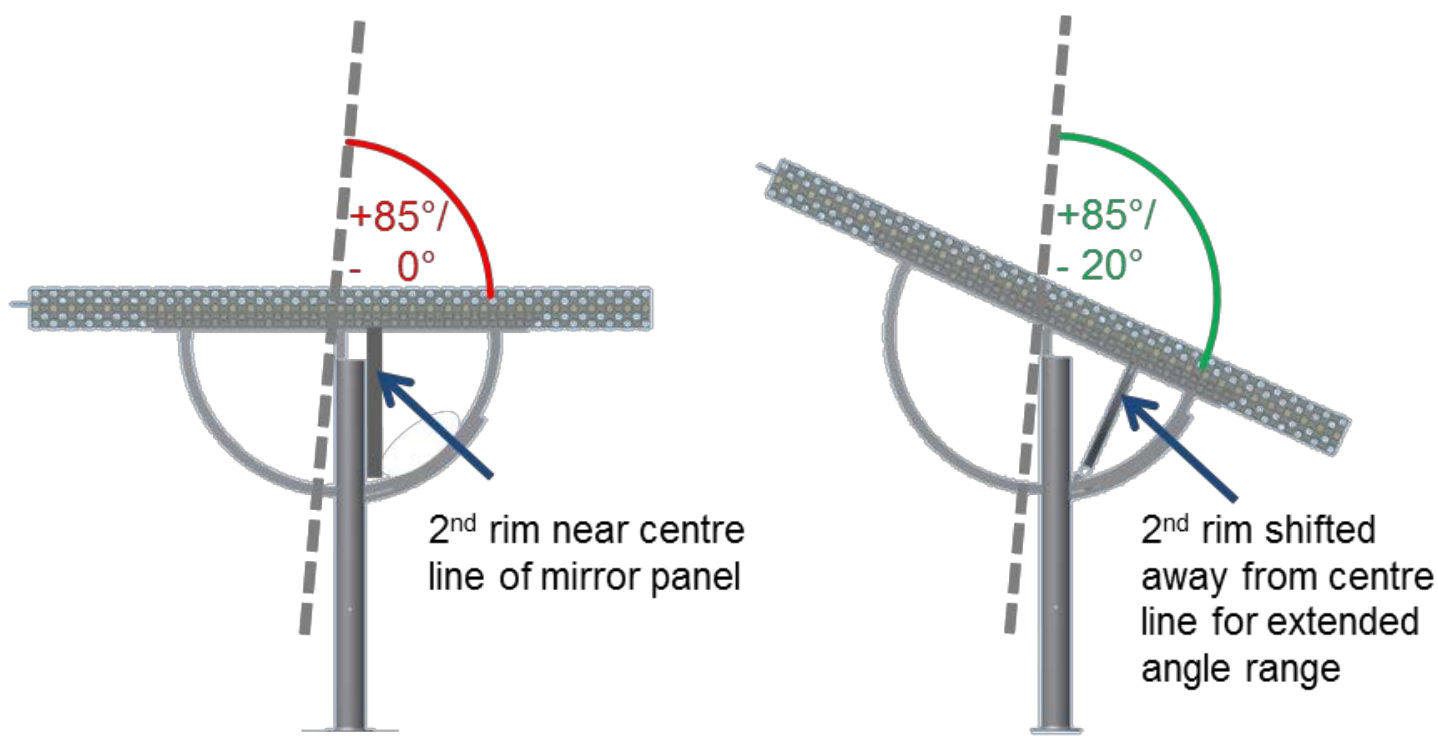

Fig. 10. Angle range limits of primary axis for $2^{\text {nd }}$ rim near centre line which leads to collision with pylon for horizontal mirror panel (left) and for shifted $2^{\text {nd }}$ rim to enable elevation of $-20^{\circ}$ (right)

Regarding stiffness it would be best to place the $2^{\text {nd }}$ rim near the centre line of the mirror panel (Fig. 10, left). But, because of collision of the $2^{\text {nd }}$ rim with the pylon, the mirror could be inclined only in one direction and a limited angle range of $+85^{\circ} / 0^{\circ}$ would result, with unacceptable losses in annual energy yield especially near the tower, see Fig. 11 (tower at position $0 \mathrm{~m} / 0 \mathrm{~m}$, north upward). These losses were calculated by using subroutines of the ray tracing code MIRVAL (Leary and Hankins, 1997) with site latitude $37^{\circ}$, altitude $600 \mathrm{~m}$ and without blocking and shading to keep the calculations as general as possible and to allow for positioning of the heliostats on a regular grid for simplification of the calculations. For a square of $200 \mathrm{~m}$ side length around the tower the heliostats were positioned with $10 \mathrm{~m}$ distance to each other. Outside of this square the resolution of the heliostat positions is $50 \mathrm{~m}$. The annual energy yields of each heliostat position was calculated for heliostats with and without angle range limitations and related to each other to calculate the relative losses of every position caused by the angle range limitations. Slope error and tracking error do not vary with time. Therefore, these errors are of almost no impact on the relative losses and had not to be accounted for. Shading and blocking differ with time and are highest in the early morning or late afternoon with low inclination of the sun. The losses due to the angle range limitations are also highest for low inclination of the sun. Therefore, neglecting blocking and shading, leads to a slight overestimation of the losses due to the angle range limitations. Hence, the calculations are conservative. 


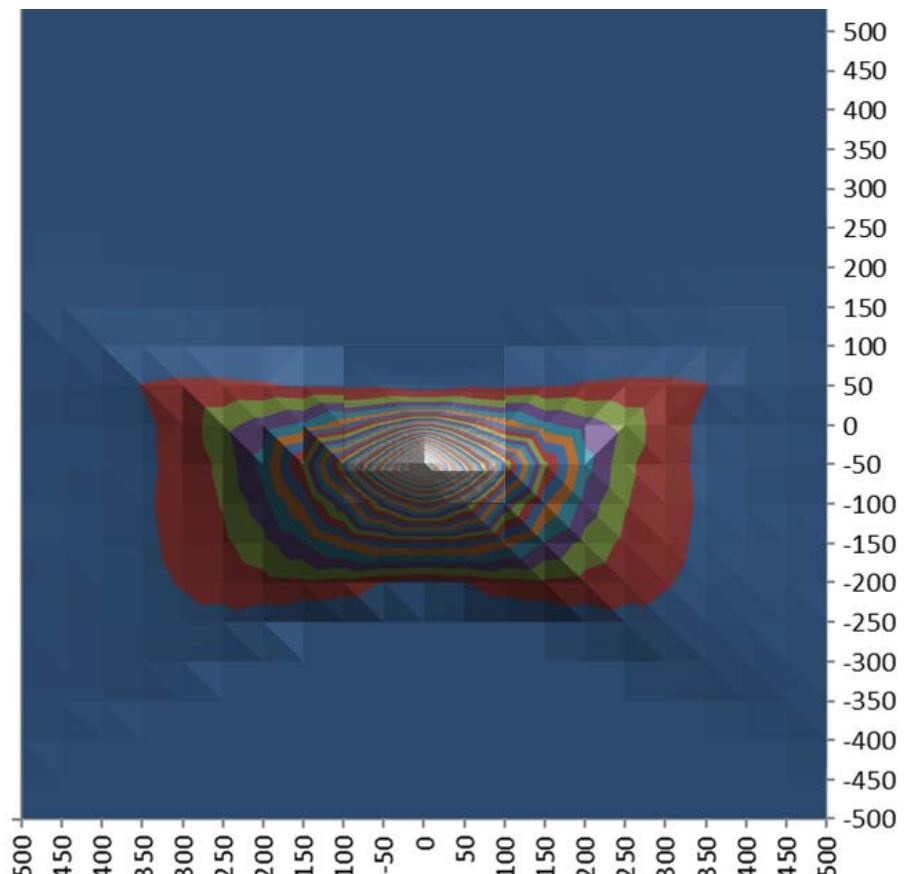

\begin{tabular}{|c|c|}
\hline$=21-22$ & $=43-4$ \\
\hline$=20-21$ & $=42-4$ \\
\hline 를 $19-20$ & $=41.42$ \\
\hline ㄹ 18.19 & $=40-41$ \\
\hline$=17-18$ & $=39$. \\
\hline 르 $16-17$ & 38 \\
\hline 르 $15-16$ & $=37-3$ \\
\hline =14-15 & $=36$ \\
\hline 린 134 & $=35$ \\
\hline 뵤 $12-1$ & 34 \\
\hline 미 $11-12$ & $=33-3$ \\
\hline 르 10-11 & $132-3$ \\
\hline ․ 9.10 & $=31.3$ \\
\hline 르 8.9 & $=30-3$ \\
\hline ㅁ․8 & $=29.3$ \\
\hline E 6.7 & $=28-2$ \\
\hline ㄷ․ 6 & $=27-2$ \\
\hline$=4.5$ & $=26-2$ \\
\hline ㅁ 3.4 & $=25-2$ \\
\hline 드 2-3 & $=24-2$ \\
\hline 드 1-2 & $=23-2$ \\
\hline$=0.1$ & $=22.7$ \\
\hline
\end{tabular}

Fig. 11. Losses due to limited angle range of primary axis $\left(+85^{\circ} \% 0^{\circ}\right)$ as percentage of annual energy yield, tower height $120 \mathrm{~m}$ (position $0 \mathrm{~m} / 0 \mathrm{~m}$ ), optimized orientations of horizontal primary axis (distances from tower in $\mathrm{m}$, north upwards)

If the $2^{\text {nd }}$ rim is shifted away from the centre line to enable an angle range of $+85^{\circ} /-45^{\circ}$, all optical orientations which are needed can be reached. In Fig. 10, right, a compromise with an angle range of $+85^{\circ} /-20^{\circ}$ is shown. The drawbacks regarding stiffness are low and the optical losses are negligible for optimized orientations of the horizontal primary axis of each heliostat (see Fig. 12).

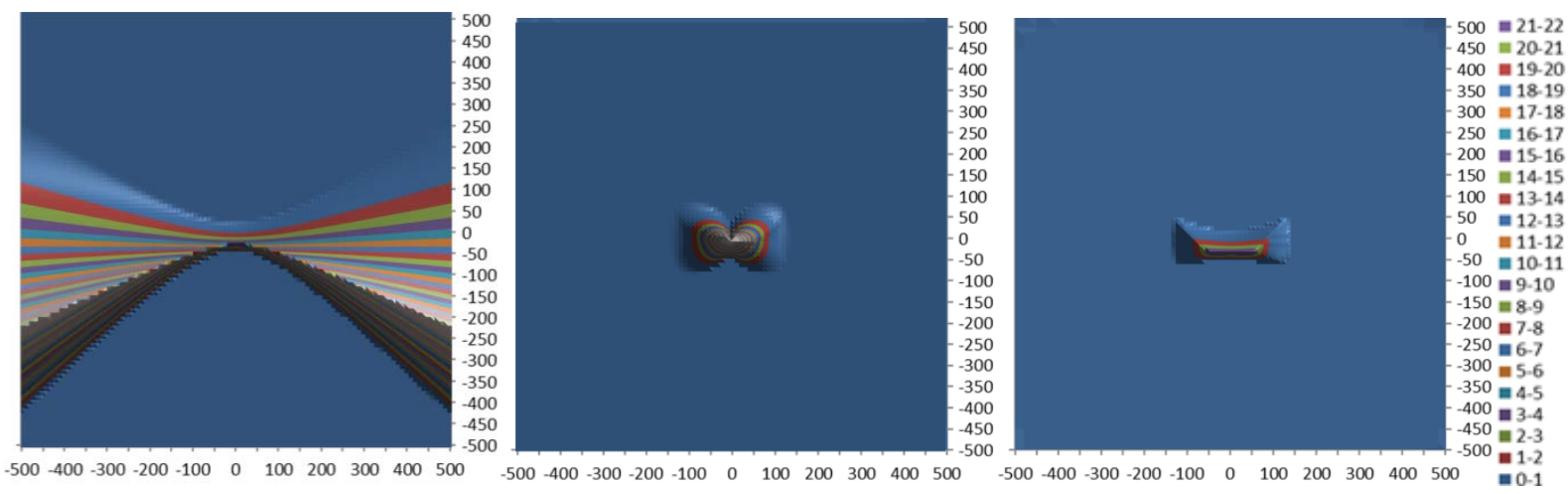

Fig. 12. Losses due to compromised angle range of primary axis $\left(+85^{\circ} /-20^{\circ}\right)$ as percentage of annual energy yield, receiver height $120 \mathrm{~m}$; orientation of horizontal primary axis: east west

(left), tangential to circles around tower (middle) and optimized (right)

The orientation of the horizontal primary axis of each heliostat was varied from $0^{\circ}$ to $360^{\circ}$ in $10^{\circ}$-steps to find the orientation with highest annual energy yield. The optimized orientations are shown in Fig. 13 and are close to orientations tangential to circles around the tower. Losses occur only in the southern part of the field close to the tower where inclinations below $-20^{\circ}$ are needed (Fig. 12 right). These low inclinations occur in the early morning and late evening hours with low DNI and high shading of the heliostats. Therefore, if the plant is in operation only for elevation of the sun higher than $10^{\circ}$, no additional loss at all would occur. 


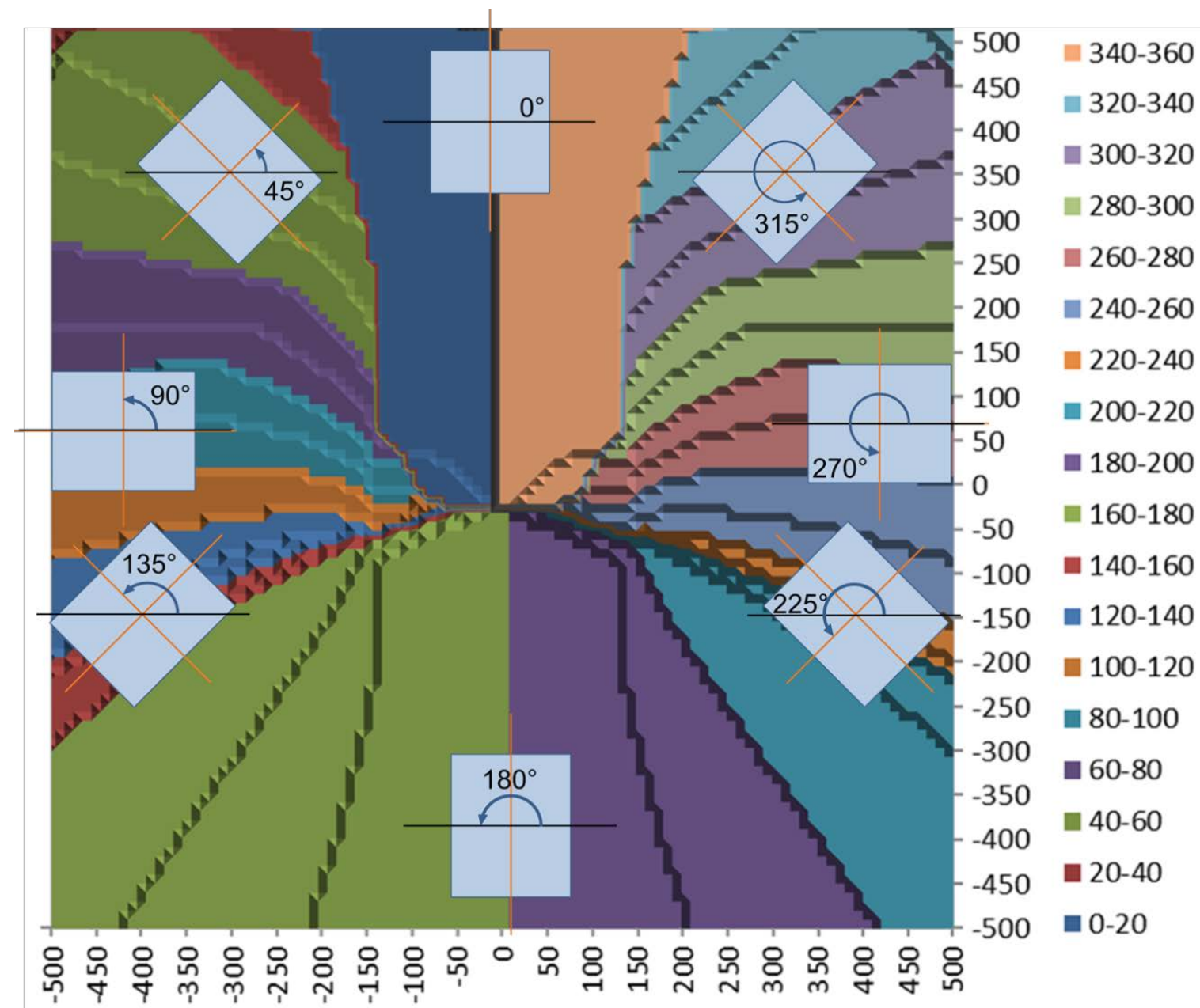

Fig. 13. Optimized horizontal primary axis orientations $\left(0^{\circ}:=\right.$ east-west orientation, $90^{\circ}:=$ northsouth orientation, receiver height $120 \mathrm{~m}$ )

For reduced tower height the losses near the tower reduce, while they increase at distances bigger than the accordant usual plant sizes (see Fig. 14). For an angle range of $+90^{\circ} /-20^{\circ}$ or for sun elevation angles higher than $10^{\circ}$ and an angle range of $+85^{\circ} /-20^{\circ}$ no loss at all would occur. 

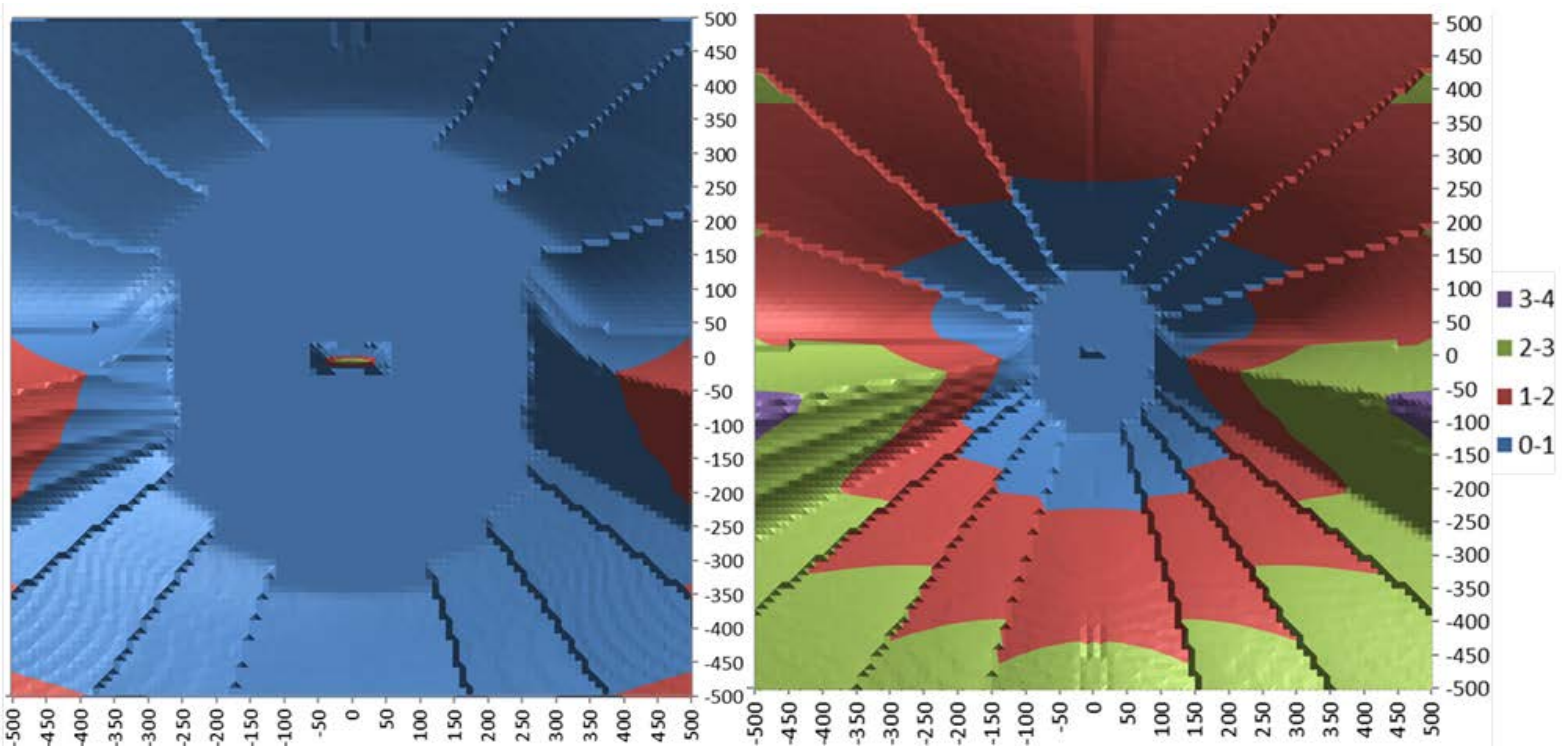

Fig. 14. Losses due to compromised angle range of primary axis $\left(+85 \%-20^{\circ}\right)$ as percentage of annual energy yield, receiver centre height $50 \mathrm{~m}$ (left), $20 \mathrm{~m}$ (right), optimized orientations of horizontal primary axis

For the second axis of rotation an angle range of $+70^{\circ} /-70^{\circ}$ is sufficient for all heliostat positions (compare (Cordes et al., 2012) and (Haberstroh et al., 2012)).

\subsection{Dimensioning}

To estimate the weight and the cost of the steel structure it was dimensioned using FEM (Finite Element Method) exposed to a typical wind loading. The mirror facet itself has been modelled as sandwich plate with glass as front layer, an inhomogeneous foam core and steel as back layer. The inhomogeneity of the foam core is designed, i.e. the foam density is locally tuned, which is a capability of the mass production process. The supporting structure, as well as the pylon, has been modelled as standard profiles and tubes. For the simulation of the rims an unstructured mesh has been used with about 100.000 elements to evaluate rigidity and stiffness.

According to the dimensioning of an $8 \mathrm{~m}^{2}\left(2.5 \times 3.2 \mathrm{~m}^{2}\right)$ heliostat, the weight of the pylon is $15 \mathrm{~kg}$, of the two rims $15 \mathrm{~kg}$, of the central bar $10 \mathrm{~kg}$ and of the guidance bar $5 \mathrm{~kg}$. The (blue) Lprofile frame mounted on the facet (see Fig. 7) is not needed for sufficient thickness of the sandwich facet and if enforcements of the steel back layer at the interfaces with the rims are foreseen. Overall, a weight of $45 \mathrm{~kg}$ for the steel structure (without mirror facet) result. Assuming steel cost of $3 \$ / \mathrm{kg}$ the cost for the steel structure is $140 \$$ or $18 \$ / \mathrm{m}^{2}$.

\section{Low cost motors with new commutation scheme and low cost sensors}

For the critical movement to stow position, which has to happen quite fast compared to normal tracking operation, an innovative circuitry used to drive the motor allows for smaller, more cost effective stepper motors. Stepper motors are popular in heliostat drives, because they offer high precision and long lifetime at low cost, as well as comparatively high torque at low speed. However, with standard drive electronics, the motors have to be oversized to allow for a safe operation, avoiding step-loss while overloaded, or have to be combined with self-locking gears which are in principle of low efficiency (around 40\%). A new, patented commutation scheme (Moeller and Speck, 1997) enables to operate the motors with the characteristics of a DC drive: The motors will slow down while overloaded, and speed up again when load is reduced (Fig. 15). The fact that the motors can be dimensioned without a 
safety margin reduces their weight and associated cost by $50 \%$. As the method works without additional sensors, no cost is added to the drive electronics. Because no self-locking gear has to be used, the energy consumption of the drive train is reduced by a factor of 2.5 .
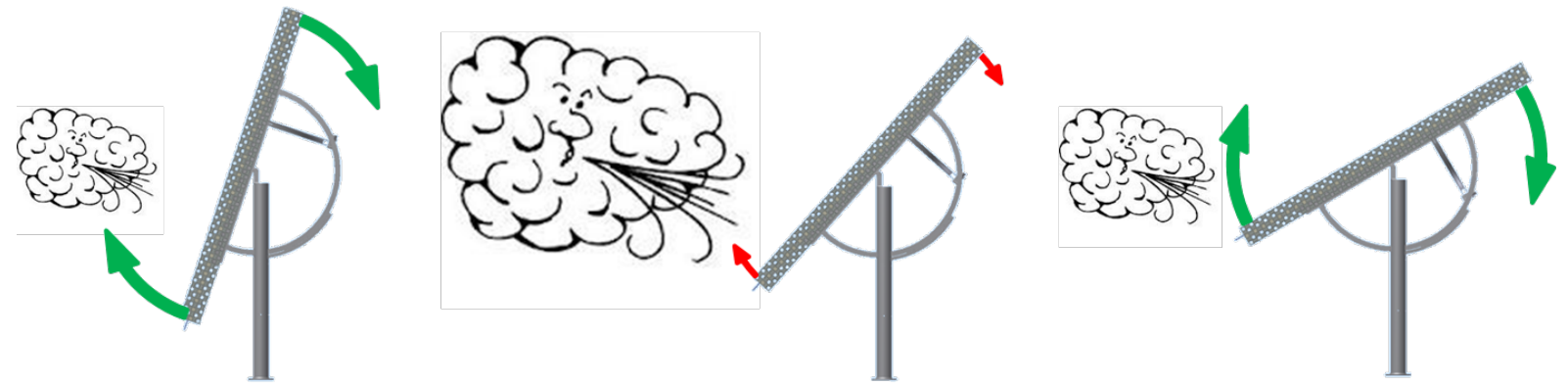

Fig. 15. Speed adaption according to load to reduce motor size and to avoid self-locking gears of low efficiency

More opportunities for cost reduction but also technical challenges are to be found in the field of sensor integration. The rims are a suitable place to embed active or passive magnetic sensor targets, e.g. magnetic tapes or inductive targets. This enables high precision / low cost direct measurements of the angle. Traditional heliostat designs typically depend on open loop operation with homing switches or additional sensors at the motor shaft. Because of the back lash of the gear boxes - worm gear or linear - the precise position is unknown and there is no base for closed loop control and active position maintenance.

\section{Wireless communication and energy supply}

Usually, the cost for wiring of heliostats is significant, especially for (a large amount of) small heliostats, and if local regulations demand for placing wires deeply underground. According to Kolb et al. (2007), Figure A-6, e.g. $20 \%$ of the total cost is needed for wiring of small heliostats with $8 \mathrm{~m}^{2}$, while for big heliostats with $150 \mathrm{~m}^{2}$ mirror area $5 \%$ are needed. Autonomy of heliostats, realized by making use of wireless communication techniques, makes cabling to a large extent dispensable and thus avoids this cost while increasing flexibility at the same time. Further cost reduction is achieved by the saved lightning protection: It is not necessary, because only striken heliostats would be affected by a lightning strike, and not the complete field. Therefore, the heliostat will be equipped with a wireless communication system based on IEEE 802.15.4 compliant transceiver hardware. Advantage is the low-power consumption, e.g. about $30 \mathrm{~mW}$ in transmission mode, and its low-cost. The unit price is in the range of $5 \$$ and the use of the ISM $2.4 \mathrm{GHz}$ radio band allows a licence-free deployment all over the world. The maximum data-rate of a single heliostat amounts to $250 \mathrm{kBit} / \mathrm{s}$ which is sufficient to completely operate the heliostat.

Large-scale, dense wireless networks necessitate measures to ensure collision-free communication to tens of thousands heliostats. Recent protocols for mesh networking, e.g. ZigBee, do not meet the soft real-time requirements of large-scale industrial plants. For this reason, a dedicated communication system was developed as shown in Fig. 16. Scalability, i.e. the accommodation of large heliostat fields, is achieved by the use of multiple radio channels, the deployment of distributed gateways to access the mesh network allowing spatial reuse of radio channels, a high interoperability of the network infrastructure supporting wireless as well as wired controlled heliostats, and a hierarchical organization. Moreover, redundancy and the fault-tolerant design of the communication system lead to a high degree of reliability. Encryption and security measures are applied to provide integrity and confidentially. In case of an emergency, all heliostats are driven immediately into stow 
position (Unterschütz and Turau, 2012). This technique relies on periodic beaconing of the current network state to all heliostats. Driving a heliostat into stow position is triggered either by an explicit request in the beacon, or by the non-arrival of a beacon, which indicates disturbances of the communication system.

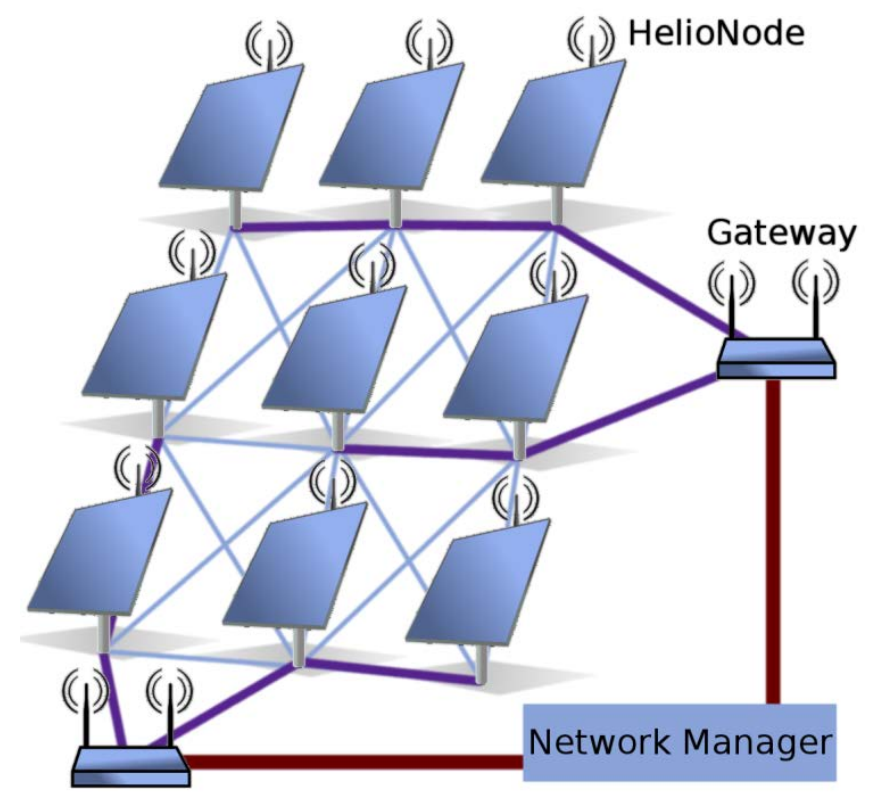

Fig. 16: Physical network architecture of wireless communication system

The wireless mesh communication, as described by Kubisch et al. (2011), was in the meantime successfully tested and improved at the German Jülich experimental power plant. A simulation tool for the whole communication process was developed in order to demonstrate the functional capability in plants of large-scale. In general, the developed system has proven to be a technology for the use in future power tower plants.

To enable autonomous operation, the heliostat will also be equipped with a photovoltaic panel for energy harvesting as well as with a super capacitor, serving as an energy storage device. However, the far more efficient drive train of the new heliostat design enables a significant reduction of size and, more relevant, associated cost of the components. The replacement of self-blocking, but inefficient mechanical components by an efficient continuous closed loop position control enables to drive down cost for energy harvesting and buffering. Savings of at least $50 \%$ are feasible as the size of the PV panel as well as the capacitance of the energy storage can be cut by half.

\section{Conclusions and outlook}

The new heliostat design reflects the trend to replace heavy, inefficient structures by lightweight systems equipped with smarter electronics and more sensors. The resulting cost reductions of the single components are significant: The costs for the sandwich mirror facets are $40 \$ / \mathrm{m}^{2}$ and for the steel structure $18 \$ / \mathrm{m}^{2}$. The cost for foundation, which typically contributes about $10 \%$ to the total cost, depends on the kind of ground and therefore cannot be given generally but a significant cost reduction due to the ground anchor solution is expected. Wiring, which would cause $20 \%$ of the total cost, is avoided. The additional cost for PV and energy storage and the motor cost are reduced by $50 \%$ because of the high efficient drive train which furthermore has presumably high tracking accuracy because winch wheels have quasi no back lash. The high slope accuracy and reflectivity of sandwich facets and the higher field density due to the horizontal primary axis leads to savings of $5-8 \%$ which is taken 
into account at the cost estimations. Overall, the cost goal of $120 \$ / \mathrm{m}^{2}$ for the heliostat field can be achieved with the new heliostat concept (for high production rate and if values for overhead and profit according to (Kolb et al., 2007) of $20 \%$ can be assumed). To achieve also the ambitioned cost target of $75 \$ / \mathrm{m}^{2}$, further cost reduction can be realized, especially by new laminated mirror concepts, by optimizing the size of the heliostat and by taking new findings regarding wind load determination (Banks, 2011) into account. To prove the concept and the cost estimations, a prototype of $8 \mathrm{~m}^{2}$ will be build.

\section{Acknowledgment}

The German Federal Ministry for the Environment, Nature Conservation and Nuclear Safety (BMU) intends to support the investigations. The authors also thank the reviewers and the associated editor for their helpful suggestions to improve the paper.

\section{References}

Banks, D., 2011. Measuring Peak Wind Loads on Solar Power Assemblies. Proc. ICWE13, Amsterdam, Netherlands.

Cordes, S., Prosinečki, T.C., Wieghardt, K., 2012. An Approach to Competitive Heliostat Fields, Proc. SolarPACES 2012 conference, Marrakesh, Morocco.

Diver, R. B., Grossman, J. W., 1999. Sandwich Construction Solar Structural Facets, Proc. of Renewable and Advanced Energy Systems for the 21st Century, ASME Int. Solar Energy Conf., Maui, HI, USA.

EN 1991-1-4, 2005. Eurocode 1: Actions on Structures - Part 1-4: General Actions - Wind Actions, European Standard, Brussels, Belgium.

Eurocode 7: Geotechnical design EN 1997. DIN 4023: Geotechnical Investigation and Testing Graphical presentation of logs of boreholes, trial pits, shafts and adits.

Gary, J., Turchi, C., Sieger, N., 2011. CSP and the DOE Sunshot Initiative, Proc. SolarPACES 2011 conference, Granada, Spain.

Gong, B., Wang, Z., Li, Z., Zang, C., Wu, Z., 2013. Fluctuating Wind Pressure Characteristics of Heliostats, Renewable Energy 50, 307-316.

Haberstroh, H., Keck, T., Weinrebe, G., Wöhrbach, M., Husenbeth, C., von Reeken, F., Balz, M., 2012. Optimization of Heliostat Axes Orientations to Reduce Annual Angular Ranges, Proc. SolarPACES 2012 conference, Marrakesh, Morocco.

Holze, C., Brüggen, H., Misseeuw, R., Cosijns, B., Albers, R., Isaza, D., Buck, R., Pfahl, A., 2012. Laminated Solar Thin Glass Mirror Solution for Cost Effective CSP Systems, Proc. SolarPACES 2012 conference, Marrakesh, Morocco.

Kolb, G.J., Jones, S.A., Donnelly, M.W., Gorman, D., Thomas, R., Davenport, R., Lumia, R., 2007. Heliostat Cost Reduction Study, SANDIA Report SAND2007-3293, Albaquerque, New Mexico, USA.

Kolb, G.J., Ho, C.H., Mancini, T.R., Gary, J.A., 2011, "Power Tower Technology Roadmap and Cost Reduction Plan", SANDIA Report SAND2011-2419, Albaquerque, New Mexico, USA.

Kubisch, S., Randt, M., Buck, R., Pfahl, A., Unterschütz, S., 2011. Wireless Heliostat and Control System for Large Self-Powered Heliostat Fields, Proc. SolarPACES 2011 conference, Granada.

Leary, P.L., Hankins, J.D., 1979. A User's Guide for MIRVAL - A Computer Code For Comparing Designs of Heliostat-Receiver Optics for Central Receiver Solar Power Plants. Sandia Laboratories Report, SAND77-8280.

Mancini, T.R., 2000. Catalog of Solar Heliostats, SolarPACES report No. III-1/00.

Moeller, S., Speck, E., 1997. Circuit Configuration for Affecting the Step Frequency in the WindingCurrent Activation of Stepping Motor Drives with Chopped Power Output Stages, patent no. US000005959426A / DE000019609803C1.

Peterka, J.A., Hosoya, N., Bienkiewicz, B., Cermak, J.E., 1986. Wind Load Reduction for Heliostats, Report SERI/STR-253-2859, Solar Energy Research Institut, Golden, Colorado, USA. 
Peterka, J.A., Tan, Z., Cermak, J.E., Bienkiewicz, B., 1989. Mean and Peak Wind Loads on Heliostats. Journal of Solar Energy Engineering, 111, 158-164.

Pfahl, A., 2011. Schwenkvorrichtung und Heliostat, German patent application 102011056341.

Pfahl, A., Buselmeier, M., Zaschke, M., 2011. Determination of Wind Loads on Heliostats, Proc. SolarPACES 2011 conference, Granada, Spain.

Pfahl, A., 2014. Survey of Heliostat Concepts for Cost Reduction, Solar Energy Engineering, 136.

Prosinečki, T.C., Schnatbaum, L., 2012. Improvements in Solar Field Layout and Molten Salt Solar Tower System Design, Proc. SolarPACES 2012 conference, Marrakesh, Morocco.

Scheffler, W., 2006. Introduction to the Revolutionary Design of Scheffler Reflectors. Proc. International Conference on Solar Cookers, Granada, Spain.

Schramek, P., Maass, J., 2010. High Efficient Heliostat Field Design for Solar Tower Systems, Proc. SolarPACES 2010 conference, Perpignan, France.

Teufel, E., Buck, R., Pfahl, A., Böing, G., Kunert, J., 2008. Dimensioning of Heliostat Components Under Wind and Gravity Load: the Map Approach, Proc. SolarPACES 2008 conference, Las Vegas, Nevada, USA.

Unterschütz, S., Turau, V., 2012. Reliable Signaling an Emergency Shutdown in Large-Scale, Wireless Controlled Industrial Plants, Proc. 10th ACM International Symposium on Mobility Management and Wireless Access (MOBIWAC '12), Paphos, Cyprus Island. 